\title{
Foodborne anisakiasis and allergy
}

Fiona J. Baird ${ }^{1,2,4}$, Robin B. Gasser², Abdul Jabbar² and Andreas L. Lopata ${ }^{1,2,4 *}$

1 School of Pharmacy and Molecular Sciences, James Cook University, Townsville, Queensland, Australia 4811

2 Centre of Biosecurity and Tropical Infectious Diseases, James Cook University, Townsville, Queensland, Australia 4811

${ }^{3}$ Department of Veterinary Science, The University of Melbourne, Victoria, Australia

${ }^{4}$ Centre for Biodiscovery and Molecular Development of Therapeutics, James Cook University, Townsville, Queensland, Australia 4811

* Correspondence. Tel. +61 4781 14563; Fax: +61 747816078

E-mail address: andreas.lopata@jcu.edu.au 


\begin{abstract}
Parasitic infections are not often associated with first world countries due to developed infrastructure, high hygiene standards and education. Hence when a patient presents with atypical gastroenteritis, bacterial and viral infection is often the presumptive diagnosis. Anisakid nematodes are important accidental pathogens to humans and are acquired from the consumption of live worms in undercooked or raw fish. Anisakiasis, the disease caused by Anisakis spp. often manifests with very similar clinical symptoms to that of bacterial and viral gastroenteritis and with the globalisation of the seafood industry, the risk of acquiring anisakiasis in developed countries is currently underestimated. The importance of this type of infection is not in its initial manifestation, which can often become chronic if the immune response does not eradicate the worm, but in its subsequent sensitisation of the patient. This sensitisation to Anisakis-derived allergens can put the patient at risk of an allergic exacerbation upon secondary exposure. This review explores this food-borne nematode, its hosts and global distribution, and its allergenic proteins.
\end{abstract}

Keywords:

Anisakis

Allergen

Allergy

Anisakiasis

Fish

Food-borne parasite

Nematode 


\section{Introduction}

Gastrointestinal worms represent a huge global burden of disease, with more than 2.5 billion people infected [1]. These worms are usually contracted through the ingestion of infective eggs or larvae, or through larval penetration of the skin [2]. Traditionally, these parasites are much more prevalent in developing than developed countries [3]. Some nematodes, such as Necator americanus (hookworm) and Trichuris trichiura (whipworm), are actually thought to be beneficial in preventing the development of allergy and other chronic inflammatory conditions, such as colitis, through their anti-inflammatory or immune-modulatory excretory/secretory (ES) molecules [4-6]. In contrast, other nematodes, such as Anisakis simplex sensu stricto (s.s.), are the causes of such allergic diseases [7, 8].

Anisakid nematodes (Nematoda: Anisakidae) affect a growing number of people in developed countries. Commonly reported species are Anisakis simplex (s.s.) and Anisakis pegreffii, and are known as herring, seal or cod worms. They were first implicated as a cause of gastrointestinal illness in 1876 [9], with immunological confirmation in the early 1980s [10, 11]. The causative agent was later described by van Thiel [12] in a Dutch patient, who had consumed raw herring. Since this discovery, more than 20,000 cases have been reported worldwide, with the majority of cases being in Japan, where, today, 2,000-3,000 cases are reported annually [13, 14]. Anisakidosis refers to the disease caused by any member of the family Anisakidae, whereas anisakiasis is caused by members of the genus Anisakis. The present review focuses on anisakiasis and its significance in relation to chronic, allergic conditions.

\section{Anisakid biology}

Different anisakids can be found in different cetacean hosts, depending on local environments $[2,15,16]$. Genetically confirmed $A$. simplex (s.s.) has been recorded in nine species of cetacean hosts, whereas A. pegreffii has been found as an adult in three species of dolphin (family Delphinidae) [17]. Infected cetacean definitive hosts excrete Anisakis eggs in their faeces into the aquatic environment. Individual first- (L1) and then second-stage (L2) larvae develop inside these eggs. Larvated eggs then hatch to release motile, free-living $L 2 s$, which are ingested by crustaceans intermediate hosts, in which L2s develop to third-stage (L3) larvae [2]. L3-infected crustaceans are then consumed by fish or squid (paratenic hosts), in which, L3s penetrate the intestine and encapsulate in tissues, particularly of the mesentery and liver. Other paratenic hosts, such as lamprey [18], fish and cephalopods [2, 19], can also be involved and accumulate L3s in a similar way. Cetaceans then consume L3-infected fish and squid, after which the $\mathrm{L} 3 \mathrm{~s}$ are released and then develop to fourth-stage larvae (L4s) and subsequently to adult stages (males and females) in the stomach (Figure 1).

Humans are accidental hosts in the anisakid life cycle. Humans infected by ingesting raw or undercooked fish or squid can be affected by anisakiasis, of which there are gastric, intestinal, ectopic and allergic forms [20-23]. Gastric anisakiasis often has a rapid onset, with the patient experiencing epigastric pain, nausea, vomiting and low-grade fever [23]. Intestinal anisakiasis is usually characterised by intermittent or constant abdominal pain, five to seven days following ingestion of infected fish or squid, with possible complications, such as peritonitis and/or ascites [21]. Ectopic 
anisakiasis, also known as extra-gastrointestinal or intra-peritoneal anisakiasis, results when ingested larvae penetrate the stomach or intestinal wall and then migrate into and through the viscera [22, 24]. In contrast, an allergic reaction can also result from anisakid infections, reflected in urticaria, gastrointestinal signs, angioedema and/or anaphylaxis [7]. Clinical signs can subside following endoscopic-guided removal of larvae from the gut, and a diagnosis can be made by identifying the worms using microscopic or molecular techniques [25].

\section{Molecular identification and classification of anisakids}

There are many species of Anisakis and almost each of them has variation in their host and geographical distributions, and in biology (reviewed in [17]). For example, it has been reported that A. simplex (s.s.) penetrates the musculature of Scomber japonicas (mackerel) better than A. pegreffii, leading to better establishment and higher intensity of infection [26]. Anisakis represents a complex of species [16], and related to species of Pseudoterranova and Contracaecum based on the presence of three bilobed lips, a ventral boring tooth and large excretory glands [20, 25, 27]. Based on larval morphology, there are two main clades (I and II). Clade I includes Anisakis simplex (s.s.), Anisakis pegreffii, Anisakis simplex C, Anisakis sp., Anisakis typica, Anisakis ziphidarum and Anisakis nascettii, with the former three sibling species representing the $A$. simplex complex. Clade II comprises of Anisakis physeteris, Anisakis brevispiculata and Anisakis paggiae [28], characterised morphologically by their long, sigmoidal ventriculus and thin, long, and uneven male spicules [28].

However, members of the Anisakis complex cannot be readily identified to species using traditional, morphological methods [29], such that molecular approaches are often used [27]. Biochemical methods have been employed [30], but PCR-coupled approaches have been more suitable, because they allow the specific amplification of genomic DNA from minute amounts of fresh, frozen or ethanol-fixed material from individual nematodes (larvae). Critical for the identification of worms to the species level is the use of reliable genetic markers. The first and second internal transcribed spacers (ITS-1 and ITS-2, respectively) of nuclear ribosomal DNA have proven useful for the specific or genotypic identification of many anisakids [31, 32]. The sequence differences between or among species is usually much higher than variation within species [33].

Mutation scanning-coupled sequencing of ITS-1 and/or ITS-2, followed by phylogenetic analysis of sequence data, is presently the best approach to identify and classify operational taxonomic units of Anisakis (see Figure 2) and related nematodes, such as Hysterothylacium and Contracaecum species $[32,34-38]$. This approach has been widely used for the high resolution analysis of genetic variation in ITS-1 and/or ITS- 2 amplicons of up to 500 bp [39]. The phylogenetic analyses of ITS- 1 and/or ITS-2 sequence data mostly support the original taxonomic division of Anisakis species into two clades [32, $34,38,40$ ]. This division is further supported by mitochondrial cytochrome coxidase 2 (cox2) sequence data sets as well as allozyme electrophoretic data, which confirm that Clade I comprises the $A$. simplex complex (i.e. A. simplex (s.s.), A. pegreffii and A. simplex C), A. typica, A. ziphidarum, and Anisakis sp. and that Clade II includes A. physeteris, A. brevispiculata, and A. paggiae [17, 28]. Importantly, members of Clade I, such as $A$. simplex s. s., $A$. pegreffii, $A$. simplex $C$, are recognised as the principal causative agents of anisakiasis (reviewed in [41, 42]).

\section{Geographical and host distributions}


The Anisakis species within Clade I are distributed mainly in the Atlantic Ocean, and the East and West Pacific, where their definitive hosts (family Delphinidae) are common. The distribution of $A$. simplex (s.s.) and A. pegreffii both extends throughout the Mediterranean sea, with both species reaching as far north as the Arctic Circle and as far south as theAntarctic waters [43]. Multiple anisakid species can be isolated from one parasitised fish. For example, Scomber japonicus (chub mackerel) caught in Japan was found to harbour both $A$. simplex (s.s.) and A. pegreffii larvae, and other species [41]. Interestingly, it has been hypothesised that anisakiasis in Japan is mainly caused by $A$. simplex (s.s.), because it seems to penetrate the muscle tissue at a higher rate than $A$. pegreffii, leading to a higher exposure rate when mackerel is eaten [26]. One study reported that the diversity of multiple anisakid species in parasitised fish decreased with latitude, as more species were isolated from fish in northern compared with southern regions [37].

Geographical regions in which human anisakiasis are common include Japan, Europe and countries in Africa and South America - here anisakids can be found consistently in fish caught locally. In northern Morocco, for instance, A. pegreffii has been found in Trachurus trachurus (horse mackerel) caught in both Atlantic or Mediterranean waters, yet no A. simplex (s.s.) has been isolated from this species of fish [44]. In Italy, Anisakis species have been found in numerous species of fish from the Ligurian Sea, but $A$. pegreffii was found at a high prevalence in T. trachurus [45]. A. pegreffii can also be found in different squid species, such as Todaropsis eblanae (lesser flying squid), Todarodes sagittatus (European flying squid) and Todarodes angolensis (Angola flying squid); and, A. simplex (s.s.) occurs in the first two aforementioned species as well as in Illex coindetii (southern shortfin or broadtail shortfin squid) [17]. There is also evidence that $A$. simplex has been isolated from Petromyzon marinus (sea lamprey), which means that $A$. simplex distribution is more widespread than first thought and the sea lamprey, which migrates to fresh-water areas may act as a transport or paratenic host [18]. Interestingly, when Pagellus bogaraveo (blackspot seabream) was sampled from the regions of Peniche and Matosinhos in Portugal, all fish species examined were found to be infected with either A. simplex (s.s.) or A. pegreffii, with the lowest prevalence (36\%) being in the Azores region [37]. Anisakis typica has been found in Trichiuris lepturus (cutlass fish) at a prevalence of $20.3 \%$, with 1-10 larvae per fish in Brazil [46]. There is also a high prevalence of Anisakis species in Merluccius australis (southern hake) in Chilean waters [47].

Commercial fishing is not limited to these geographical areas, and anisakids have been found in polar regions, with $A$. simplex $\mathrm{C}$ being found in Antarctic fishes, including Notothenia coriiceps (black rockcod) and Notothenia rossii (marbled rockcod) [48]. Recently, in the Yellow Sea, China, one study reported a prevalence of $A$. pegreffii of $25 \%$ in eight different fish species, namely Astroconger myriaster (whitespotted conga), Clupea pallasii (Pacific herring), Coryphaena hippurus (mahi-mahi or common dolphinfish), Lophius litulon (yellow goosefish), Mugil cephalus (flathead mullet), Pneumatophorus japonicas (Atlantic chub mackerel), Scomberomorus niphonius (Japanese Spanish mackerel or Japanese seerfish) and/or Sebastiscus marmoratus (false kelpfish) [49]. Six years later, the first clinical case of anisakiasis was reported in China [50]. Recent studies from Australasia also demonstrated prevalences of up to $100 \%$ for species including Neoplatycephalus richardson (tiger flathead) and Sillago flindersi (eastern school whiting) from temperate waters, and Scomberomorus commerson (narrow-barred Spanish mackerel) and Sphyraena forsteri (Bigeye barracuda) from tropical waters $[27,31,35,36,51]$.

\section{Prevalence in humans}


Ingestion of anisakid larvae typically leads to a self-limiting infection, which sensitises the human host to Anisakis allergens (cf. section 7). The country with the highest prevalence of Anisakis infections in humans is Japan. Infected sushi and sashimi (national dishes of raw fish) are a significant source of human infection, with 2,000-3,000 cases of anisakiasis being reported annually [14]. The globalisation of provincial cuisine has also increased the number and distribution of consumers eating raw fish. Other regional dishes, such as salted or pickled herring (Holland and Nordic countries), gravlax (Nordic countries), boquerones (Spain), lomi-lomi (Hawaii) and ceviche (South America), also appear to have contributed to an increase in anisakiasis in humans. It is recognised that $A$. simplex (s.s.) is the main causative agent of anisakidosis in Japan, as determined by polymerase chain reaction (PCR)-based restriction fragment length polymorphism (RFLP) analysis of the ITS- 1 and ITS-2 regions [52] and its relatively high prevalence in chub mackerel and other fish species [26, 31, 41].

In Italy, where marinated and/or raw fish is a culinary tradition in some regions, the actual incidence of anisakiasis is believed to be grossly underestimated in humans due to a high prevalence of parasitised fish in the Mediterranean region [17]; high consumption rates of these fish indicate a high risk of human infection [53]. In Italy, there have been multiple reports of quite complicated clinical cases of anisakiasis in humans linked to A. pegreffii. This anisakid was identified using PCR-RFLP from a Southern Italian patient suffering from gastric anisakiasis [54]. In another case in Viterbo, Italy, $A$. pegreffii was molecularly identified and confirmed as a cause of granulomatous lesions in a patient suffering from anisakiasis [53]. This nematode has also been associated with multiple cases of gastroallergic anisakiasis in multiple locations of Italy [55].

Whilst anisakiasis is a common disease in Japan and Italy, clinical cases have also been reported from other countries. In 2011, the first human anisakidosis case was reported in Adelaide, South Australia, after a patient had consumed raw, locally caught mackerel [56]. In China, the first report of anisakiasis in a 56 year old male patient suffering from chronic diarrhoea for one month was published recently [50]. During hospitalisation, the Chinese patient was suspected to have colon cancer, and the parasite had not been detected in his stomach. Had the correct diagnosis not been made, their illness may have been treated inappropriately with surgical removal of healthy tissue, without an alleviation of his clinical symptoms. This year also marks the first case of anisakiasis presenting as a bowel obstruction in a child in Croatia [57] and the first anisakid detected in an endocervical adenocarcinoma in a German-American female from the United States of America [58].

Exposure of fish consumers to Anisakis spp. can be assessed by establishing the prevalence of anti-Anisakis antibodies or their immune-responsiveness to Anisakis antigens. In addition skin-prick testing can be conducted using extracts from $A$. simplex, which however have to be generated inhouse $[59,60]$. In Northern Morocco, for example, a sero-prevalence of $5.1 \%$ was recorded, with a higher number of sensitized people between the ages of 31 and 43 years [61]. However, no cases of anisakiasis or patent Anisakis infections have been reported for these people. In Brazil, where there appear to be no reported cases of anisakiasis in humans, a sero-prevalence of $20.9 \%$ was recorded in a cohort of military personnel $(n=67)$ that regularly consumed seafood suggesting a significant association between fish consumption and serology to $A$. simplex [62].

In another study, conducted in Italy, patients of more than 65 years of age, suffering from chronic urticaria, were tested for hypersensitivity to $A$. simplex antigens; $55 \%$ of these patients had anti- $A$. simplex serum antibodies and $35 \%$ of them were also reactive to house dust mite [63]. These findings 
were supported by similar results from an earlier study [64], in which the prevalence of anti-Anisakis antibodies did not correlate with fish-eating habits, acute or chronic gastrointestinal disease and/or abdominal surgery. Nevertheless, it could be shown, using a murine model, that Anisakis proteins can generate urticaria and systemic hypersensitivity to Anisakis antigens in the absence of an acute infection [65]. In addition, inhalation of Anisakis-derived proteins can induce severe respiratory symptoms and sensitisation in mice [66]. Moreover, in a study of fish-processing workers [59], 8\% of employees demonstrated specific IgE responses against an extract from A. simplex (s.s.) L3s. The magnitude of allergic symptoms related to the extent of fish consumption. The induction of allergic reactions in Anisakis-sensitised patients, and the role of live Anisakis larvae or Anisakis-derived proteins in these allergic reactions remains to be fully elucidated [67]. In the meantime, the allergens from $A$. simplex and $A$. pegreffii are medically important in human populations, in which there is high risk of exposure, and requires detailed investigation.

\section{Allergic responses in humans and Anisakid allergens}

Although some helminths do not usually induce allergic responses in humans, anisakids often do. Clinical signs include urticaria, rhinitis, bronco-constriction, cough and/or gastrointestinal responses $[2,20]$. Often, acute allergic reactions can be seen, with no or minor gastrointestinal problems. On the other hand, sometimes, gastrointestinal symptoms occur without an allergic component. In relation to anisakids, the predominant response seems to be Th2-mediated, resulting in the expulsion of the parasite. Th2-driven immune responses include the production of IgE antibody, the recruitment of eosinophils, mast cells and basophils, goblet cell hyperplasia, smooth muscle contraction and vascular fluid release, which assist in the removal of the parasite $[2,25,68]$. Sensitised individuals develop specific IgE antibodies to a range of allergenic proteins described in the following. These antibodies bind to receptors on the surface of a variety of cells, including mast cells in the gastrointestinal tract and the skin, and circulating basophils in the blood. Upon contact with allergenic proteins, the interaction of the IgE antibody with the allergen triggers cells to release a range of inflammatory mediators, resulting in clinical signs through mucus secretion, eosinophil accumulation and the release of cytokines and histamine. Diagnostically, IgE immunoblotting has been used to test patients for allergic responses to known $A$. simplex allergens, in addition to skin-prick tests and direct measurement using the ImmunoCAP system [69, 70].

To date, 13 allergens of $A$. simplex (s.s.) have been described, many of which have been well characterised by molecular methods (see Table 1). Patients may be exposed primarily to somatic antigens originating from live or dead larvae in fish products, because many allergens of Anisakis are heat and/or pepsin resistant [71, 72], and most of them have been detected in excretory-secretory (ES) products [72-81]. The major allergens of Anisakis (recognized by IgE antibodies in sera from more than $50 \%$ of patients) are considered to be Ani s 1 and Ani s 7 [73], although, in one study [75], Ani s 5 was recognized by serum antibodies in $49 \%$ of patients (41/84). The $24 \mathrm{kDa}$ Ani s 1 was recognized by serum IgE antibodies in $67-85 \%$ of patients with gastroallergic anisakiasis, but not by asymptomatic individuals [81]. This latter allergen, which is secreted by the worm, shows homology to serine protease inhibitors from Caenorhabditis elegans and represents two different isoforms. Ani s 1 is heat stable and can act as a food allergen, causing clinical reactions upon secondary exposure, immediately following ingestion of cooked fish [78]. The other major allergen, Ani s 7, is also an ES product of 
approximately $139 \mathrm{kDa}$, and is a glycoprotein [82]. This molecule was shown to be recognized by serum IgE antibodies in all patients ( $n=60)$ with allergy to Anisakis $[73,82]$.

Another allergen is Ani s 4 , a heat-stable cystatin that is recognized by sera from $27 \%$ of affected patients, but appears to be central in eliciting anaphylaxis [79]. Heat-stable allergens, such as Ani s 4, are important, even if classified as "minor allergens" (due to the frequency of recognition by patient sera), because these allergens relate to allergic reactions to cooked or canned (anisakid-infected) fish [80]. Other minor allergens include Ani s 5 (15 kDa), Ani s 8 (15 kDa) and Ani s 9 (14 kDa), which all share protein sequence homology, and are members of the SPX/RAL-2 family, which is specific to nematodes. All of these allergens are heat-stable ES products, although Ani s 9 is reportedly more abundant in crude somatic extracts from Anisakis [80], and their biological function is unknown. Interestingly, another minor allergen, Ani s $6(7 \mathrm{kDa})$, is homologous to serine protease inhibitors from Boophilus microplus (cattle tick), Anopheles stephensi (mosquito) and Glossina morsitans morsitans (tsetse fly), including the Apis mellifera (honeybee) allergen Api $\mathrm{m} 6$.

The remaining two allergens described to date, namely Ani s 2 (100 kDa) and Ani s 3 (41 kDa), are homologues of the muscle proteins paramyosin and tropomyosin, respectively, and are thought to be primarily responsible for cross-reactivity between Anisakis and other invertebrates, such as prawns and house dust mite [83-86]. Although these proteins appear to be important in eliciting allergic reactions to Anisakis in humans [73,87], they are homologous to major allergens of insects and crustaceans [8, 88], and might elicit immunological cross-reactivity or even cross-sensitivity. Interestingly, nematode tropomyosins might also represent vaccine candidates, as they have been shown to elicit antibody-mediated protective immunity against different larval stages of the Trichostrongylus colubriformis (trichostrongyloid nematode) and the Onchocerca volvulus (filarioid nematode) [89]. Similarly, a recent study has shown that serum antibodies against haemoglobin of $A$. pegreffii were able to induce immunogenic responses in mice against infection with Nippostrongy/us brasiliensis (hookworm) [90].

Anisakiasis can generate different stages of severe hypersensitivity in patients. Spain, similar to Italy, has a high prevalence of anisakiasis in humans in coastal regions, resulting in frequent reports of hypersensitivity [91-93]. Here, allergy against Anisakis has been associated with HLA class II alleles. In Basque country, the frequency of DQB1*0202, DQB1*0601 and DQB1*0603 alleles in allergic patients was significantly increased compared with other patient groups [94], which may account for the higher incidence rate. Allergic patients in parts of Spain have also been confirmed to react to specific allergens including rAni s 1, nAni s 4, rAni s 5, rAni s 9 and rAni s 10 (rather than the unidentified allergens), whilst also having higher rates of urticaria and gastrointestinal symptoms compared to similarly affected Italians [70]. Italian patients however showed IgE reactivity to the twelve characterised allergens and various, presently unidentified allergens [70].

The identification and characterisation of novel allergens is ongoing for most causative agents of allergic conditions. Traditionally, allergens were identified using affected patient sera against prokaryotically expressed recombinant proteins [95]. Currently, phage display libraries are being developed as the phenotype is expressed directly on the virus, allowing for more expedient analysis. This technique has been applied to $A$. simplex, and thirty novel allergen candidates have been identified but have yet to be confirmed experimentally [96]. Also bioinformatic approaches are supporting these methods. Sequence, physiochemical and structural predictions can also be 
conducted inexpensively, without processing a single specimen. Putative and potential allergens can be identified using known allergen sequences from related eukaryotes to identify novel allergens in a species that has yet to be studied. This is particularly useful in identifying potential cross-reactive associations between allergens. In 2013, seven novel putative allergens in Cicer arietinum L. (chickpea) were identified using this method, and potential cross-reactivity to known allergens, such as Ara $\mathrm{h} 8$ (peanut), Gly $\mathrm{m} 4$ (soyabean), Vig 1 (mungbean) and Bet v 1 (Birch pollen), were also predicted [97]. Alternatively, utilising known patterns of allergenicity (motifs) from multiple diverse allergens using software such as AllerHunter, AlgPred, APPEL, ProAp and AllerTOP, can be utilised to identify putative allergens from unrelated species. This approach has been successful at distinguishing between allergenic and non-allergenic proteins, and might be universally applied [98]. Although bioinformatic approaches cannot replace molecular biological studies, they can guide targeted experimentation.

\section{Food safety considerations}

The consumption of food and food products has altered over the last few centuries due to the development of transportation, agriculture, population growth and globalisation. The World Health Organisation states that the total consumption of fish has been increasing at a rate of $3.6 \%$ per year since 1961 [99]. The average apparent consumption per capita increased from approximately $9 \mathrm{~kg}$ in the early 1960s to $16 \mathrm{~kg}$ in 1997, showing that demand has nearly doubled in 40 years [99]. Between $13.8 \%$ and $16.5 \%$ of our daily diet of the animal protein intake is derived for fish, crustaceans and molluscs, while fish provides 20-30 kcal per capita per day [99]. Approximately $20 \%$ of the world's population attains at least one-fifth of its animal protein intake from fish [99]. Of the fish consumed, two thirds is obtained from capture fisheries in marine and inland waters, whilst one third is derived from aquaculture. All wild caught freshwater and seawater fishes are at risk of harbouring parasitic nematodes [100], hence visual inspection of unprocessed fish gut cavity was implemented as a form of quality control. However this type of inspection was shown to be unreliable for parasites and cannot be considered as a successful Hazard Analysis Critical Control Point (HACCP) in food production [101]. Many countries have different regulations and/or non-mandatory guidelines for the control of nematodes, such as $A$. simplex in fish and fish products, particularly for importation. Within the European Union lightly cured fish, intended to be eaten without further cooking, should be frozen at $-20^{\circ} \mathrm{C}$ for at least 24 hours to kill any live nematodes in the product [102]. Other countries, such as the United Kingdom, Australia, USA and Canada, have similar national food safety guidelines. The detection of these nematodes in fresh and processed fish products has been successful using realtime PCR [103-105], UV fluorescent imaging [106], IgG antibody immunoblotting [107] and enzymelinked immunosorbent assay [108]. 


\section{Conclusion}

Anisakis simplex and A. pegreffii are well known parasitic pathogens of humans in countries such as Japan, where the provincial cuisine includes raw or under cooked fish. In the last few years, these nematodes have been newly discovered in Chinese and Australian waters, where local fish species act as paratenic hosts. Recently, sea lamprey has been described as a new paratenic host, which could account for the spread of Anisakis larvae into both fresh and sea waters [18]. The increased number of new host records and expansion in the geographical ranges of Anisakis spp. suggest that the risk of anisakiasis infections is underestimated. With any emerging infection, surveillance of the at-risk population is paramount, particularly given that the presence of Anisakissensitised individuals can have long-term health implications. Improved diagnosis of anisakiasis using molecular or serological approaches is warranted, as anisakiasis can be misdiagnosed as bacterial or viral gastroenteritis, leading to an under-reporting of the problem. The Anisakis allergen Ani s 3 has demonstrated cross-reactivity with house dust mite allergens [86], which is a ubiquitous allergen that could cause anaphylaxis in severely affected, allergic patients. It is for these reasons that food-borne anisakiasis should be considered as an emerging health risk for any humans that consume large quantities of fish known to be paratenic hosts for these Anisakis spp.

\section{Acknowledgements}

Financial support from the Australian Research Council (ARC) to ALL is acknowledged. ALL is holder of an ARC Future Fellowship. Financial support from a JCU Centre of Biodiscovery \& Molecular Development of Therapeutics Seed Grant to FJB is acknowledged. The Gasser Lab is supported by grants from the ARC and the National Health and Medical Research Council (NHMRC) is gratefully acknowledged. 


\section{References}

1. World Health Organisation. Soil-transmitted helminths Geneva, Switzerland: World Health Organisation; 2012 [cited 2012 December 12]. Available from: http://www.who.int/intestinal_worms/en/.

2. Audicana MT, Kennedy MW. Anisakis simplex: from obscure infectious worm to inducer of immune hypersensitivity. Clin Microbiol Rev. 2008; 21(2):360-79.

3. Brooker S. Estimating the global distribution and disease burden of intestinal nematode infections: Adding up the numbers - A review. Int J Parasitol. 2010; 40(10):1137-44.

4. Ferreira I, Smyth D, Gaze S, Aziz A, Giacomin P, Ruyssers N, et al. Hookworm excretory/secretory products induce IL-4+IL-10+CD4+ T cell responses and suppress pathology in a mouse model of colitis. Infect Immun. 2013.

5. Navarro S, Ferreira I, Loukas A. The hookworm pharmacopoeia for inflammatory diseases. Int J Parasitol. 2013; 43(3-4):225-31.

6. Hunter MM, McKay DM. Review article: helminths as therapeutic agents for inflammatory bowel disease. Aliment Pharmacol Ther. 2004; 19(2):167-77.

7. Lopez-Serrano MC, Gomez AA, Daschner A, Moreno-Ancillo A, de Parga JM, Caballero MT, et al. Gastroallergic anisakiasis: findings in 22 patients. J Gastroenterol Hepatol. 2000; 15(5):503-6.

8. Lopata AL, Lehrer SB. New insights into seafood allergy. Curr Opin Allergy Clin Immunol. 2009; 9(3):2707.

9. Leuckart R. Die menschlichen Parasiten und die von ihren herriihrenden Krankheiten. C F Winter'sche Verlagsbuchhandlung. Leipzig, Germany1876.

10. Asaishi K, Nishino C, Ebata T, Totsuka M, Hayasaka H, Suzuki T. Studies on the etiologic mechanism of anisakiasis. --1. Immunological reactions of digestive tract induced by Anisakis larva. Gastroenterol Jpn. 1980; 15(2):120-7.

11. Takemoto Y, Tsuji M. Detection of Anisakis larvae crude antigen specific lgE by means of enzyme linked immunosorbent assay. Arerugi. 1985; 34(7):403-10.

12. van Thiel P, Kuipers FC, Roskam RT. A nematode parasitic to herring, causing acute abdominal syndromes in man. Trop Geogr Med. 1960; 12:97-113.

13. Chai J-Y, Darwin Murrell K, Lymbery AJ. Fish-borne parasitic zoonoses: Status and issues. Int J Parasitol. 2005; 35(11-12):1233-54.

14. Yorimitsu N, Hiraoka A, Utsunomiya H, Imai Y, Tatsukawa H, Tazuya N, et al. Colonic intussusception caused by anisakiasis: a case report and review of the literature. Intern Med. 2013; 52(2):223-6.

15. Kliks MM. Human anisakiasis: an update. J Am Med Assoc. 1986; 255(19):2605.

16. Anderson RC. Nematodes parasites of vertebrates: their development and transmission. Wallingford, U. K. : CAB International; 2000. p. 272-3.

17. Mattiucci S, Nascetti G. Chapter 2 Advances and Trends in the Molecular Systematics of Anisakid Nematodes, with Implications for their Evolutionary Ecology and Host-Parasite Co-evolutionary Processes. In: Rollinson D, Hay SI, editors. Advances in Parasitology. Volume 66: Academic Press; 2008. p. 47-148.

18. Bao M, Garci ME, Antonio JM, Pascual S. First report of Anisakis simplex (Nematoda, Anisakidae) in the sea lamprey (Petromyzon marinus). Food Control. 2013; 33(1):81-6.

19. Pascual S, Abollo E. Whaleworms as a tag to map zones of heavy-metal pollution. Trends in Parasitol. 2005; 21(5):204-6.

20. Hochberg NS, Hamer DH, Hughes JM, Wilson ME. Anisakidosis: Perils of the Deep. Clin Infect Dis. 2010; 51(7):806-12.

21. Ishikura H, Kikuchi K, Nagasawa K, Ooiwa T, Takamiya H, Sato N, et al. Anisakidae and anisakidosis. Prog Clin Parasitol. 1993; 3:43-102.

22. Ito $\mathrm{Y}$, Ikematsu $\mathrm{Y}$, Yuzawa $\mathrm{H}$, Nishiwaki $\mathrm{Y}$, Kida $\mathrm{H}$, Waki $\mathrm{S}$, et al. Chronic gastric anisakiasis presenting as pneumoperitoneum. Asian J Surg. 2007; 30(1):67-71.

23. Kakizoe S, Kakizoe H, Kakizoe K, Kakizoe Y, Maruta M, Kakizoe T, et al. Endoscopic findings and clinical manifestation of gastric anisakiasis. Am J Gastroenterol. 1995; 90(5):761-3.

24. Nawa Y, Hatz C, Blum J. Sushi delights and parasites: the risk of fishborne and foodborne parasitic zoonoses in Asia. Clin Infect Dis. 2005; 41(9):1297-303.

25. Roongruangchai J, Tamepattanapongsa A, Roongruangchai K. Stereo and scanning electron microscopic studies of the third stage larvae of Anisakis simplex. Southeast Asian J Trop Med Public Health. 2012; 43(2):287-95. 
26. Suzuki J, Murata R, Hosaka M, Araki J. Risk factors for human Anisakis infection and association between the geographic origins of Scomber japonicus and anisakid nematodes. Int J Food Microbiol. 2010; 137(1):88-93.

27. Shamsi S, Gasser R, Beveridge I. Genetic characterisation and taxonomy of species of Anisakis (Nematoda : Anisakidae) parasitic in Australian marine mammals. Invertebr Syst. 2012; 26(2):204-12.

28. Valentini A, Mattiucci S, Bondanelli P, Webb SC, Mignucci-Giannone AA, Colom-Llavina MM, et al. Genetic relationships among Anisakis species (Nematoda: Anisakidae) inferred from mitochondrial cox2 sequences, and comparison with allozyme data. J Parasitol. 2006; 92(1):156-66.

29. Quiazon KMA, Yoshinaga T, Ogawa K, Yukami R. Morphological differences between larvae and in vitrocultured adults of Anisakis simplex (sensu stricto) and Anisakis pegreffii (Nematoda: Anisakidae). Parasitol Int. 2008; 57(4):483-9.

30. Podolska M, Napierska D. Acetylcholinesterase activity in hosts (herring Clupea harengus) and parasites (Anisakis simplex larvae) from the southern Baltic. ICES J Mar Sci. 2006; 63(1):161-8.

31. Jabbar A, Asnoussi A, Norbury L, Eisenbarth A, Shamsi S, Gasser RB, et al. Larval anisakid nematodes in teleost fishes from Lizard Island, northern Great Barrier Reef, Australia. Mar Freshwater Res. 2012b; 63(12):1283-99.

32. Zhu XQ, Podolska M, Liu JS, Yu HQ, Chen HH, Lin ZX, et al. Identification of anisakid nematodes with zoonotic potential from Europe and China by single-strand conformation polymorphism analysis of nuclear ribosomal DNA. Parasitol Res. 2007; 101(6):1703-7.

33. Zhu X, Gasser RB, Podolska M, Chilton NB. Characterisation of anisakid nematodes with zoonotic potential by nuclear ribosomal dna sequences. Int J Parasitol. 1998; 28(12):1911-21.

34. Umehara A, Kawakami Y, Araki J, Uchida A. Multiplex PCR for the identification of Anisakis simplex sensu stricto, Anisakis pegreffii and the other anisakid nematodes. Parasitol Int. 2008; 57(1):49-53.

35. Shamsi S, Eisenbarth A, Saptarshi S, Beveridge I, Gasser RB, Lopata AL. Occurrence and abundance of anisakid nematode larvae in five species of fish from southern Australian waters. Parasitol Res. 2011; 108(4):927-34.

36. Jabbar A, Fong RW, Kok KX, Lopata AL, Gasser RB, Beveridge I. Molecular characterization of anisakid nematode larvae from 13 species of fish from Western Australia. Int J Food Microbiol. 2013; 161(3):24753.

37. Hermida M, Mota R, Pacheco CC, Santos CL, Cruz C, Saraiva A, et al. Infection levels and diversity of anisakid nematodes in blackspot seabream, Pagellus bogaraveo, from Portuguese waters. Parasitol Res. 2012; 110(5):1919-28.

38. Abe N. Application of the PCR-sequence-specific primers for the discrimination among larval Anisakis simplex complex. Parasitol Res. 2008; 102(5):1073-5.

39. Gasser RB. Molecular tools-advances, opportunities and prospects. Vet Parasitol. 2006; 136(2):69-89.

40. D'Amelio S, Mathiopoulos KD, Santos CP, Pugachev ON, Webb SC, Picanco M, et al. Genetic markers in ribosomal DNA for the identification of members of the genus Anisakis (Nematoda: ascaridoidea) defined by polymerase-chain-reaction-based restriction fragment length polymorphism. Int J Parasitol. 2000; 30(2):223-6.

41. Arizono N, Yamada M, Tegoshi T, Yoshikawa M. Anisakis simplex sensu stricto and Anisakis pegreffii: biological characteristics and pathogenetic potential in human anisakiasis. Foodborne Pathog Dis. 2012; 9(6):517-21.

42. Pravettoni V, Primavesi L, Piantanida M. Anisakis simplex: current knowledge. Eur Ann Allergy Clin Immunol. 2012; 44(4):150-6.

43. Kuhn T, García-Màrquez J, Klimpel S. Adaptive Radiation within Marine Anisakid Nematodes: A Zoogeographical Modeling of Cosmopolitan, Zoonotic Parasites. PLoS One. 2011; 6(12):e28642.

44. Abattouy N, Lopez AV, Maldonado JL, Benajiba MH, Martin-Sanchez J. Epidemiology and molecular identification of Anisakis pegreffii (Nematoda: Anisakidae) in the horse mackerel Trachurus trachurus from northern Morocco. J Helminthol. 2013:1-7.

45. Serracca L, Cencetti E, Battistini R, Rossini I, Prearo M, Pavoletti E, et al. Survey on the presence of Anisakis and Hysterothylacium larvae in fishes and squids caught in Ligurian Sea. Vet Parasitol. 2013.

46. Borges JN, Cunha LF, Santos HL, Monteiro-Neto C, Portes Santos C. Morphological and molecular diagnosis of anisakid nematode larvae from cutlassfish (Trichiurus lepturus) off the coast of Rio de Janeiro, Brazil. PLoS One. 2012; 7(7):e40447.

47. Chavez RA, Gonzalez MT, Oliva ME, Valdivia IM. Endoparasite fauna of five Gadiformes fish species from the coast of Chile: host ecology versus phylogeny. J Helminthol. 2012; 86(1):10-5. 
48. Dzido J, Kijewska A, Rokicka M, Świątalska-Koseda A, Rokicki J. Report on anisakid nematodes in polar regions - Preliminary results. Polar Sci. 2009; 3(3):207-11.

49. Zhang L, Hu M, Shamsi S, Beveridge I, Li H, Xu Z, et al. The specific identification of anisakid larvae from fishes from the Yellow Sea, China, using mutation scanning-coupled sequence analysis of nuclear ribosomal DNA. Mol Cell Probes. 2007; 21(5-6):386-90.

50. Qin $Y$, Zhao $Y$, Ren $Y$, Zheng $L$, Dai $X, L i ~ Y$, et al. Anisakiasis in china: the first clinical case report. Foodborne Pathog Dis. 2013; 10(5):472-4.

51. Jabbar A, Khoon AT, Hui TX, Schaeffner BC, Jex AR, Nolan MJ, et al. Mutation scanning-based analysis of anisakid larvae from Sillago flindersi from Bass Strait, Australia. Electrophoresis. 2012a; 33(3):499505.

52. Umehara A, Kawakami Y, Araki J, Uchida A. Molecular identification of the etiological agent of the human anisakiasis in Japan. Parasitol Int. 2007; 56(3):211-5.

53. Mattiucci S, Paoletti M, Borrini F, Palumbo M, Palmieri RM, Gomes V, et al. First molecular identification of the zoonotic parasite Anisakis pegreffii (Nematoda: Anisakidae) in a paraffin-embedded granuloma taken from a case of human intestinal anisakiasis in Italy. BMC Infect Dis. 2011; 11:82.

54. D'Amelio S, Mathiopoulos KD, Brandonisio O, Lucarelli G, Doronzo F, Paggi L. Diagnosis of a case of gastric anisakidosis by PCR-based restriction fragment length polymorphism analysis. Parassitologia. 1999; 41(4):591-3.

55. Mattiucci S, Fazii P, De Rosa A, Paoletti M, Megna AS, Glielmo A, et al. Anisakiasis and Gastroallergic Reactions Associated with Anisakis pegreffii Infection, Italy. Emerg Infect Dis. 2013; 19(3):496-9.

56. Shamsi S, Butcher AR. First report of human anisakidosis in Australia. Med J Aust. 2011; 194(4):199-200.

57. Juric I, Pogorelic Z, Despot R, Mrklic I. Unusual cause of small intestine obstruction in a child: Small intestine anisakiasis: report of a case. Scott Med J. 2013; 58(1):e32-6.

58. Ramanan P, Blumberg AK, Mathison B, Pritt BS. Parametrial anisakidosis. J Clin Microbiol. 2013; 51(10):3430-4.

59. Nieuwenhuizen N, Lopata AL, Jeebhay MF, Herbert DR, Robins TG, Brombacher F. Exposure to the fish parasite Anisakis causes allergic airway hyperreactivity and dermatitis. J Allergy Clin Immunol. 2006; 117(5):1098-105.

60. Rodero M, Cuellar C, Chivato T, Jimenez A, Mateos JM, Laguna R. Evaluation by the skin prick test of Anisakis simplex antigen purified by affinity chromatography in patients clinically diagnosed with Anisakis sensitization. J Helminthol. 2004; 78(2):159-65.

61. Abattouy N, Valero A, Martin-Sanchez J, Penalver MC, Lozano J. Sensitization to Anisakis simplex species in the population of northern Morocco. J Investig Allergol Clin Immunol. 2012; 22(7):514-9.

62. Junior IF, Vericimo MA, Cardoso LR, Clemente SC, do Nascimento ER, Teixeira GA. Cross-sectional study of serum reactivity to Anisakis simplex in healthy adults in Niteroi, Brazil. Acta Parasitol. 2013; 58(3):399-404.

63. Ventura MT, Napolitano S, Menga R, Cecere R, Asero R. Anisakis simplex hypersensitivity is associated with chronic urticaria in endemic areas. Int Arch Allergy Immunol. 2013; 160(3):297-300.

64. Lopez-Saez MP, Zubeldia JM, Caloto M, Olalde S, Pelta R, Rubio M, et al. Is Anisakis simplex responsible for chronic urticaria? Allergy Asthma Proc. 2003; 24(5):339-45.

65. Nieuwenhuizen N, Herbert DR, Brombacher F, Lopata AL. Differential requirements for interleukin (IL)4 and IL-13 in protein contact dermatitis induced by Anisakis. Allergy. 2009; 64(9):1309-18.

66. Kirstein F, Horsnell WG, Nieuwenhuizen N, Ryffel B, Lopata AL, Brombacher F. Anisakis pegreffii-induced airway hyperresponsiveness is mediated by gamma interferon in the absence of interleukin-4 receptor alpha responsiveness. Infect Immun. 2010; 78(9):4077-86.

67. Daschner A, Cuéllar C, Rodero M. The Anisakis allergy debate: does an evolutionary approach help? Trends in Parasitol. 2012; 28(1):9-15.

68. Pulendran B, Artis D. New paradigms in type 2 immunity. Science. 2012; 337(6093):431-5.

69. García M, Moneo I, Audicana MT, del Pozo MD, Muñoz D, Fernández E, et al. The use of IgE immunoblotting as a diagnostic tool in Anisakis simplex allergy. J Allergy Clin Immunol. 1997; 99(4):497501.

70. Caballero ML, Asero R, Antonicelli L, Kamberi E, Colangelo C, Fazii P, et al. Anisakis allergy componentresolved diagnosis: clinical and immunologic differences between patients from Italy and Spain. Int Arch Allergy Immunol. 2013; 162(1):39-44.

71. Moneo I, Caballero ML, Gonzalez-Munoz M, Rodriguez-Mahillo Al, Rodriguez-Perez R, Silva A. Isolation of a heat-resistant allergen from the fish parasite Anisakis simplex. Parasitol Res. 2005; 96(5):285-9. 
72. Caballero ML, Moneo I, Gomez-Aguado F, Corcuera MT, Casado I, Rodriguez-Perez R. Isolation of Ani s 5, an excretory-secretory and highly heat-resistant allergen useful for the diagnosis of Anisakis larvae sensitization. Parasitol Res. 2008; 103(5):1231-3.

73. Anadon AM, Romaris F, Escalante M, Rodriguez E, Garate T, Cuellar C, et al. The Anisakis simplex Ani s 7 major allergen as an indicator of true Anisakis infections. Clin Exp Immunol. 2009; 156(3):471-8.

74. Caballero ML, Umpierrez A, Moneo I, Rodriguez-Perez R. Ani s 10, a new Anisakis simplex allergen: Cloning and heterologous expression. Parasitol Int. 2011; 60(2):209-12.

75. Kobayashi Y, Ishizaki S, Shimakura K, Nagashima Y, Shiomi K. Molecular cloning and expression of two new allergens from Anisakis simplex. Parasitol Res. 2007a; 100(6):1233-41.

76. Kobayashi Y, Ohsaki K, Ikeda K, Kakemoto S, Ishizaki S, Shimakura K, et al. Identification of novel three allergens from Anisakis simplex by chemiluminescent immunoscreening of an expression cDNA library. Parasitol Int. 2011; 60(2):144-50.

77. Kobayashi Y, Shimakura K, Ishizaki S, Nagashima Y, Shiomi K. Purification and cDNA cloning of a new heat-stable allergen from Anisakis simplex. Mol Biochem Parasitol. 2007b; 155(2):138-45.

78. Moneo I, Caballero ML, Gomez F, Ortega E, Alonso MJ. Isolation and characterization of a major allergen from the fish parasite Anisakis simplex. J Allergy Clin Immunol. 2000; 106(1 Pt 1):177-82.

79. Rodriguez-Mahillo Al, Gonzalez-Munoz M, Gomez-Aguado F, Rodriguez-Perez R, Corcuera MT, Caballero ML, et al. Cloning and characterisation of the Anisakis simplex allergen Ani s 4 as a cysteineprotease inhibitor. Int J Parasitol. 2007; 37(8-9):907-17.

80. Rodriguez-Perez R, Moneo I, Rodriguez-Mahillo A, Caballero ML. Cloning and expression of Ani s 9, a new Anisakis simplex allergen. Mol Biochem Parasitol. 2008; 159(2):92-7.

81. Shimakura K, Miura H, Ikeda K, Ishizaki S, Nagashima Y, Shirai T, et al. Purification and molecular cloning of a major allergen from Anisakis simplex. Mol Biochem Parasitol. 2004; 135(1):69-75.

82. Rodriguez E, Anadon AM, Garcia-Bodas E, Romaris F, Iglesias R, Garate T, et al. Novel sequences and epitopes of diagnostic value derived from the Anisakis simplex Ani s 7 major allergen. Allergy. 2008; 63(2):219-25.

83. Pérez-Pérez J, Fernández-Caldas E, Marañón F, Sastre J, Bernal ML, Rodríguez J, et al. Molecular Cloning of Paramyosin, a New Allergen of Anisakis simplex. Int Arch Allergy Immunol. 2000; 123(2):120-9.

84. Asturias JA, Eraso E, Moneo I, Martinez A. Is tropomyosin an allergen in Anisakis? Allergy. 2000a; 55(9):898-9.

85. Guarneri F, Guarneri C, Benvenga S. Cross-reactivity of Anisakis simplex: possible role of Ani s 2 and Ani s 3. Int J Dermatol. 2007; 46(2):146-50.

86. Bernardini R, Mistrello G, Novembre E, Roncarolo D, Zanotta S, Lombardi E, et al. Cross-reactivity between IgE-binding proteins from Anisakis simplex and Dermatophagoides pteronyssinus. Int J Immunopathol Pharmacol. 2005; 18(4):671-5.

87. Asturias JA, Eraso E, Martínez A. Cloning and high level expression in Escherichia coli of an Anisakis simplex tropomyosin isoform. Mol Biochem Parasitol. 2000b; 108(2):263-7.

88. Lopata AL, O'Hehir RE, Lehrer SB. Shellfish allergy. Clin Exp Allergy. 2010; 40(6):850-8.

89. Sereda MJ, Hartmann S, Lucius R. Helminths and allergy: the example of tropomyosin. Trends in Parasitol. 2008; 24(6):272-8.

90. Nieuwenhuizen NE, Meter JM, Horsnell WG, Hoving JC, Fick L, Sharp MF, et al. A Cross-Reactive Monoclonal Antibody to Nematode Haemoglobin Enhances Protective Immune Responses to Nippostrongylus brasiliensis. PLoS Negl Trop Dis. 2013; 7(8):e2395.

91. Audicana MaT, Ansotegui IJ, de Corres LF, Kennedy MW. Anisakis simplex: dangerous - dead and alive? Trends in Parasitol. 2002; 18(1):20-5.

92. Moneo I, Caballero M-L, Rodriguez-Perez R, Rodriguez-Mahillo A-I, Gonzalez-Muñoz M. Sensitization to the fish parasite Anisakis simplex: clinical and laboratory aspects. Parasitol Res. 2007; 101(4):1051-5.

93. Daschner A, Cuellar C, Valls A. Towards a differential definition of atopy: Anisakis simplex and the relationship between parasites and arthropods in respiratory allergy. Parasite Immunol. 2008; 30(8):417-24.

94. Sánchez-Velasco P, Mendizábal L, Antón EM, Ocejo-Vinyals G, Jerez J, Leyva-Cobián F. Association of hypersensitivity to the nematode Anisakis simplex with HLA class II DRB1*1502-DQB1*0601 haplotype. Hum Immunol. 2000; 61(3):314-9.

95. Burks AW, Cockrell G, Stanley JS, Helm RM, Bannon GA. Isolation, identification, and characterization of clones encoding antigens responsible for peanut hypersensitivity. Int Arch Allergy Immunol. 1995; 107(1-3):248-50. 
96. López I, Pardo MA. A phage display system for the identification of novel Anisakis simplex antigens. J Immunol Methods. 2011; 373(1-2):247-51.

97. Kulkarni A, Ananthanarayan L, Raman K. Identification of putative and potential cross-reactive chickpea (Cicer arietinum) allergens through an in silico approach. Comput Biol Chem. 2013; 47:149-55.

98. Dimitrov I, Naneva L, Doytchinova I, Bangov I. AllergenFP: allergenicity prediction by descriptor fingerprints. Bioinformatics. 2013.

99. World Health Organisation Diet, nutrition, and the prevention of chronic diseases. Report of a WHO Study Group Geneva: World Health Organisation 2003 WHO Technical Report Series, No. 797.

100. EFSA Panel on Biological Hazards (BIOHAZ). Scientific Opinion on risk assessment of parasites in fishery products. . EFSA J. 2010; 8(4):1543 [91 pp.].

101. Llarena-Reino M, González ÁF, Vello C, Outeiriño L, Pascual S. The accuracy of visual inspection for preventing risk of Anisakis spp. infection in unprocessed fish. Food Control. 2012; 23(1):54-8.

102. Wootten R, Cann DC, Great Britain. Ministry of Agriculture F, Station FTR, Station TR. Round Worms in Fish: Ministry of Agriculture, Fisheries and Food Torry Research Station; 2001.

103. Lopez I, Pardo MA. Evaluation of a real-time polymerase chain reaction (PCR) assay for detection of anisakis simplex parasite as a food-borne allergen source in seafood products. J Agric Food Chem. 2010; 58(3):1469-77.

104. Herrero B, Vieites JM, Espiñeira M. Detection of anisakids in fish and seafood products by real-time PCR. Food Control. 2011; 22(6):933-9.

105. Mossali C, Palermo S, Capra E, Piccolo G, Botti S, Bandi C, et al. Sensitive detection and quantification of anisakid parasite residues in food products. Foodborne Pathog Dis. 2010; 7(4):391-7.

106. Yang X, Nian R, Lin H, Duan C, Sui J, Cao L. Detection of anisakid larvae in cod fillets by UV fluorescent imaging based on principal component analysis and gray value analysis. J Food Prot. 2013; 76(7):128892.

107. Rodriguez-Mahillo Al, Gonzalez-Munoz M, de las Heras C, Tejada M, Moneo I. Quantification of Anisakis simplex allergens in fresh, long-term frozen, and cooked fish muscle. Foodborne Pathog Dis. 2010; 7(8):967-73.

108. Xu X, Sui J, Cao L, Lin H. Direct competitive enzyme-linked immunosorbent assay (ELISA) for rapid screening of anisakid larvae in seafood. J Sci Food Agric. 2010; 90(5):877-81. 


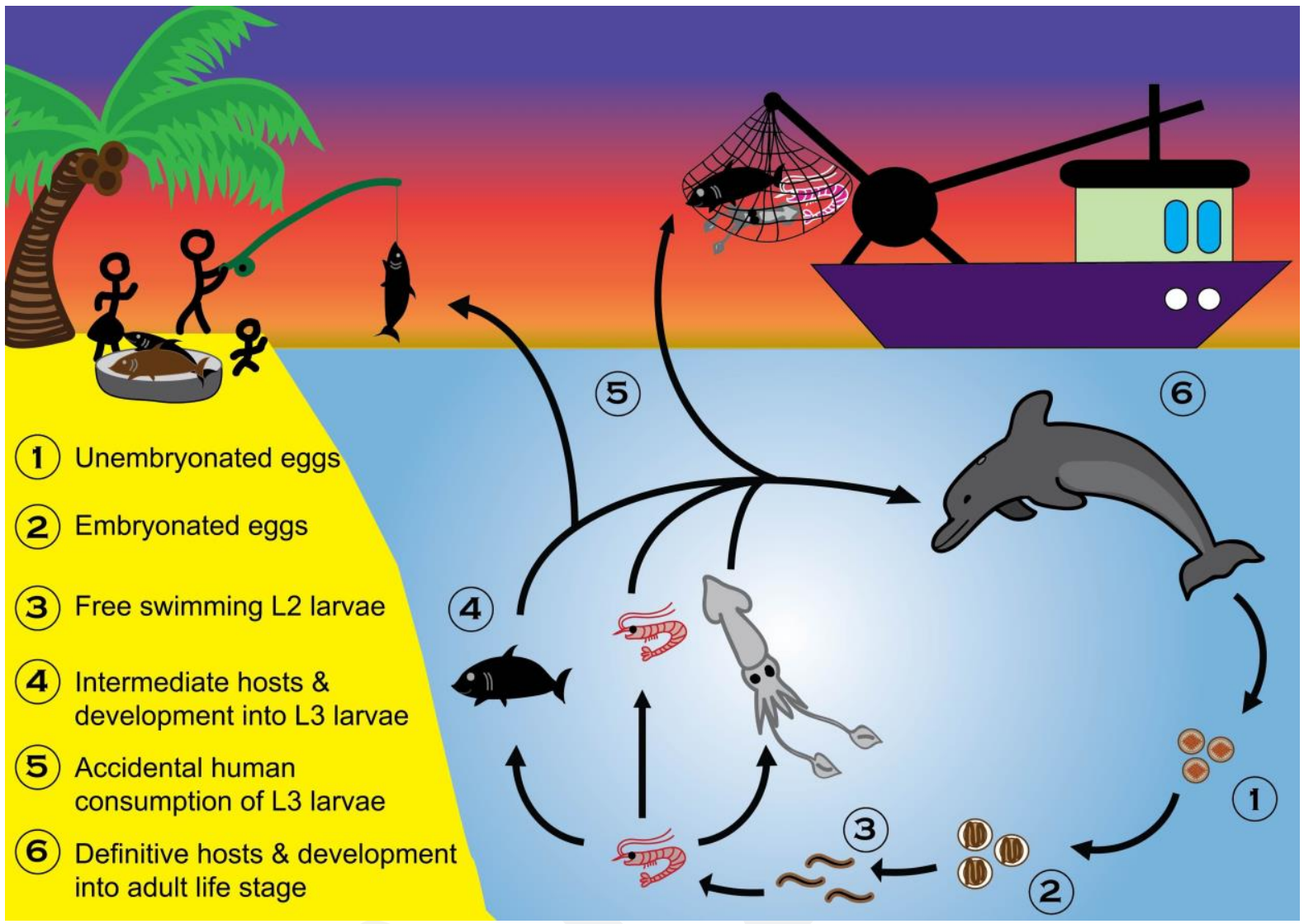

Figure 1: Life cycle of the species of Anisakis, including humans as accidental paratenic hosts. 


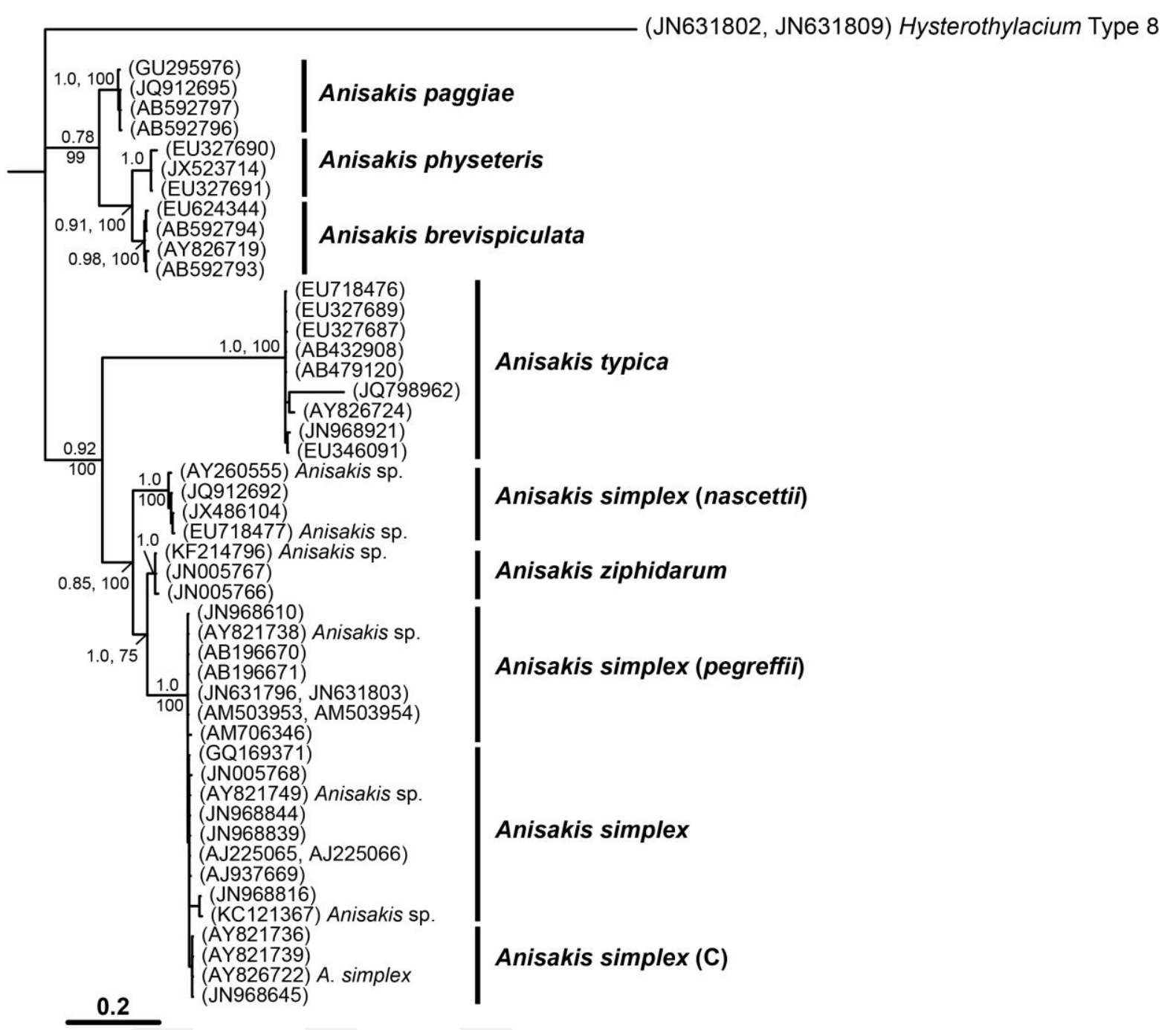

Figure 2: Genetic relationships of Anisakis species from various hosts. The relationships were inferred based on phylogenetic analyses of concatenated sequence data for the first and second internal transcribed spacers (ITS-1 and ITS-2) of nuclear ribosomal DNA using Bayesian Inference (BI) and distance-based Neighbour Joining (NJ) methods. Hysterothylacium Type 8 was used as the out-group. The topology of the BI tree (shown) was concordant with that produced using the NJ method (not shown). Nodal support is given as a posterior probability (left) for $\mathrm{BI}$ or a bootstrap value (right or below) for NJ. GenBank accession numbers of individual sequence used for the analysis are given in parentheses. The scale bar indicates the number of inferred substitutions per nucleotide site. 
Table 1: Allergens of Anisakis simplex

\begin{tabular}{llllll}
\hline Allergen & $\begin{array}{l}\text { Molecular } \\
\text { weight } \\
\text { (kDa) }\end{array}$ & $\begin{array}{l}\text { Nematode } \\
\text { antigen }\end{array}$ & Protein & $\begin{array}{l}\text { Reactivity in } \\
\text { sensitised patients }\end{array}$ & Reference \\
\hline Ani s 1 & 24 & $\begin{array}{l}\text { Excretory- } \\
\text { secretory (ES) } \\
\text { product }\end{array}$ & $\begin{array}{l}\text { Kunitz-type } \\
\text { trypsin inhibitor }\end{array}$ & $85 \%$ & {$[78]$} \\
\hline Ani s 2 & 97 & Somatic & Paramyosin & $88 \%$ & {$[83]$} \\
\hline Ani s 3 & 41 & Somatic & Tropomyosin & Unknown & {$[87]$} \\
\hline Ani s 4 & 9 & ES product & Cystatin & $27 \%$ & {$[79]$} \\
\hline Ani s 5 & 15 & ES product & SXP/RAL protein & $25-49 \%$ & {$[75]$} \\
\hline Ani s 6 & 7 & ES product & Serpin & $18 \%$ & {$[75]$} \\
\hline Ani s 7 & 139 & ES product & Glycoprotein & $83-100 \%$ & {$[73]$} \\
\hline Ani s 8 & 15 & ES product & SXP/RAL protein & $25 \%$ & {$[77]$} \\
\hline Ani s 9 & 14 & ES product & SXP/RAL protein & $13 \%$ & {$[80]$} \\
\hline Ani s 10 & 22 & Unknown & Unknown & $39 \%$ & {$[74]$} \\
\hline Ani s 11 & 55 & Unknown & Unknown & $47 \%$ & {$[76]$} \\
\hline Ani s 11-li & Unknown & Unknown & Unknown & Unknown & {$[76]$} \\
\hline Ani s 12 & Unknown & Unknown & Unknown & $57 \%$ & {$[76]$} \\
\hline
\end{tabular}

